\title{
Development of a Technique for Restoring the Fidelity of Distorted Playback Audio Signal from Analog Cassette Tape
}

\author{
A. O. Atijosan ${ }^{1 *}$, S. A. Adeniran ${ }^{1}$, M. O. Sokunbi ${ }^{1}$ and R. A. Badru ${ }^{1}$ \\ ${ }^{1}$ Department of Electronic and Electrical Engineering, Obafemi Awolowo University, Ile-Ife, \\ Osun State, Nigeria.
}

\section{Authors' contributions}

This work was carried out in collaboration between all authors. Author SAA designed the study. Authors SAA, AOA, MOS and RAB managed literature searches and analysis. Author AOA wrote the first draft of the manuscript. All authors read and approved the final manuscript.

Article Information

DOI: 10.9734/BJAST/2015/16287

Editor(s):

(1) Chien-Jen Wang, Department of Electrical Engineering, National University of Tainan, Tainan, Taiwan.

(2) Rodolfo Dufo Lopez, Electrical Engineering Department, University of Zaragoza, Spain.

Reviewers:

(1) Anonymous, Taiwan (2) Anonymous, Italy.

(3) Edward E. Ogheneovo, Department of Computer Science, University of Port Harcourt, Nigeria. Complete Peer review History: http://www.sciencedomain.org/review-history.php?iid=1139\&id=5\&aid=9401

ABSTRACT

A simple yet elegant analog based technique for restoring the fidelity of playback audio signals emanating from magnetic cassette tapes is presented. The technique makes use of information from the high frequency bias signal in magnetic cassette tapes to correct for errors in the playback audio signal. Performance evaluation of the developed technique shows that the technique can correct for errors due to noise, scratches on the tape surface, clipping, and non-linear distortion. The developed technique will be valuable in restoring the fidelity of playback audio signal from magnetic cassette tapes stored in archives and private homes.

Keywords: Magnetic cassette tapes; audio restoration; compensation technique; playback audio signal. 


\section{INTRODUCTION}

Magnetic cassette tapes were the de- facto standard for recording and preserving audio signals to a vast majority of people in the $20^{\text {th }}$ century. This has led to the abundance of audio recordings with great historical and cultural values that exist in no other format [1]. Furthermore, these recordings have proved to be irreplaceable primary sources for disciplines such as linguistics, musicology, and many more [2]. As these tapes deteriorate over time, many of the recordings can be lost to time [3,4]. Hence the need for techniques that can restore the fidelity of deteriorated playback signals from magnetic cassette tapes.

The major cause of deterioration in the quality of playback signal from magnetic tape recordings stems from wear and tear on the magnetic tape due to repeated playback and age [5]. Sources of degradations can be divided into two general groups: global degradations and localized degradations. Global degradations introduce errors in all samples of the waveform and include background noise, wow and flutter and non-linear distortion. Localized degradations are errors that affect only certain samples in the waveform, [6,7] and this include noise, clipping and scratches on the surface of the magnetic tape [8]. Errors due to non-linear defect, clipping, noise and scratches on the tape surface were considered in this study.

Errors due to non-linear defect in magnetic tapes can be modelled using sigmoid functions, [1] as

$$
h(x)=\alpha * \arctan (\beta * x)
$$

where $x$ represents the audio signal, $\beta$ defines the amplitude and $\alpha$ affects the gradient. Another form of error is clipping, which is mainly due to high recording levels. Also it can be caused by tape "dropouts" due to poor-quality media being used and dirty record heads [8]. Clipping can be modelled as

$$
h(x)=\max (\min (x, 1),-1)
$$

where $x$ represents the audio signal. Noise is a form of error in magnetic tapes that can be modelled using Additive White Gaussian Noise (AWGN) [1,9]. The effect of scratches on the tape surface can also be modelled using AWGN at higher signal to noise ratio (SNR).

A review of similar technique discussed in [1013], that utilized the high frequency bias signal in magnetic audio tapes or a reference signal to correct for errors show that the techniques has only been used in correcting for errors due to wow and flutter in the analog and digital domain and have not been developed to correct for other forms of errors especially in the analog domain. The work of [14] utilized the high frequency bias signal in the analog domain to correct for other forms of distortions but was unable to correct for errors that arises when the polarity of the error signal and that of the playback signal differs. This work aims at filling this gap.

\section{PROPOSED TECHNIQUE}

Restoration of the playback audio signal was accomplished by means of a compensation technique which is represented mathematically as

$$
\begin{aligned}
& y(t)=a(t)+m\left|\left(x_{o}(t)-x_{i}(t)\right)\right| \\
& a(t)=a_{1}(t)+v,
\end{aligned}
$$

To make $a_{1}(t)$ above zero volt, a dc offset voltage $v$ is added before the differentiation

$$
m=\frac{\frac{d a(t)}{d t}}{\left|\frac{d a(t)}{d t}\right|}
$$

where $y(t), a_{1}(t), x_{o}(t), x_{i}(t)$ are the restored audio signal, playback audio signal, playback reference signal and input reference signal respectively.

Based on the principle that the high frequency biased signal and the audio signal recorded on audio magnetic tapes have undergone the same level of distortion.The compensation equation therefore computes the error signal resulting from the high frequency bias signal to compensate for the distortion undergone by the audio signal. Equation 4 determines the polarity of the error signal required to compensate for the distortion undergone by the audio signal. This avoids the error that may arise when the polarity of the audio signal is different from that of the bias signal.The experiments were validated via simulation

\section{RESULTS AND DISCUSSION}

A typical test signal is shown in Fig. 1 (obtained from Scope 1). It is a composite of two sinusoids of frequencies $6 \mathrm{kHz}$ and $13 \mathrm{kHz}$ with different amplitudes. The test signal was subjected to some processes that simulate distortions 
experienced by playback signals. We attempted the following variations:

i. Corruption of the signal by AWGN leading to a SNR of $5 \mathrm{~dB}$.

ii. Clipping of the playback signal.

iii. Play back signal affected by scratches on the tape surface.

iv. Play back signal affected by non-linear distortions.

Results obtained using the test signal is as indicated in Figs. 2 to 6 (obtained from scope 2) and Tables 1 and 3 . A $1 \mathrm{kHz}$ monotone sinusoidal test signal subjected to clipping and nonlinear distortion was used in obtaining the result in Table 2. Comparing the test signal with the restored playback signal in Figs. 2b, 3b, 4b, $5 \mathrm{~b}$ and $6 \mathrm{~b}$, it can be observed that the distortion in the playback signal has been eliminated and the distorted playback signal restored. This demonstrates the ability of the proposed compensation technique to restore playback signal distorted by noise, clipping, nonlinearity and scratch.

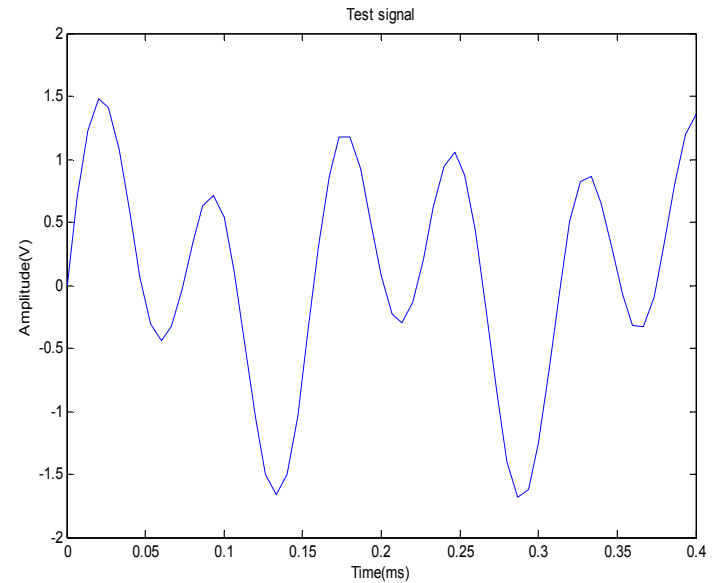

Fig. 1. Test signal (Multisine with frequencies of $6 \mathrm{kHz}$ and $13 \mathrm{kHz}$ )

An improvement of about $6 \mathrm{~dB}$ was observed when the technique is compared with [3] where a simple FIR digital filter was used to improve the output SNR of the distorted audio signal (output SNR of [3] was approximately 52dB). The techniques considered in [10-13] were only applicable to correction of wow and flutter and have not been developed to correct other forms of distortions. The technique developed in this study corrected for distortions due to noise, nonlinear distortion, clipping and scratch on the tape surface. Comparison with the technique developed in [14] shows that the develop technique can correct for distortions that arises when the polarity of the error signal $\left(x_{o}(t)-\right.$ $\left.x_{i}(t)\right)$ and that of the playback audio signal $(a(t))$ differ.

\section{Distortion due to AWGN}

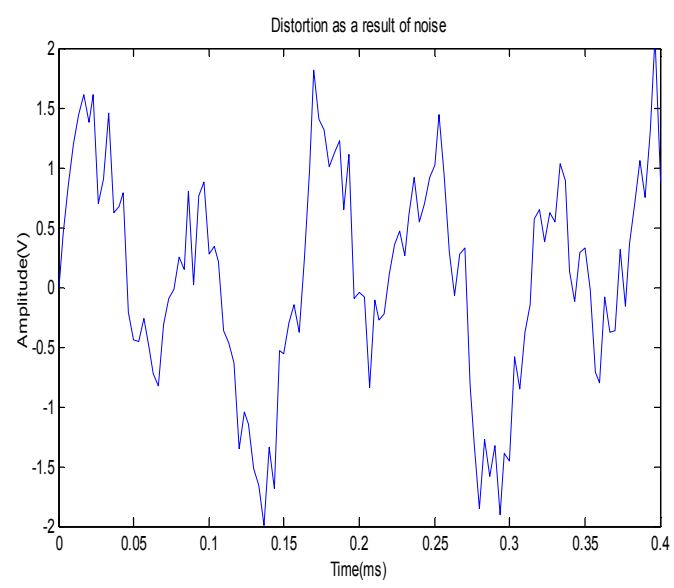

Fig. 2a. Distortion on test signal due to AWGN at input SNR of $5 \mathrm{~dB}$

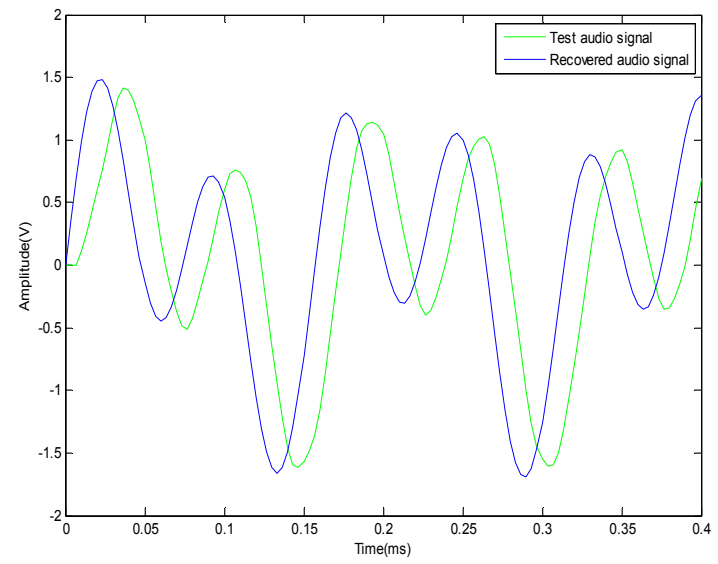

Fig. 2b. Plot of test signal and recovered signal (AWGN)

Table 1. Signal to noise ratio

\begin{tabular}{lll}
\hline Distortion & SNR of distorted playback signal & $\begin{array}{l}\text { SNR at the output (after correction } \\
\text { of distortions) }\end{array}$ \\
\hline Noise & $-2.5 \mathrm{~dB}$ & $56.6 \mathrm{~dB}$ \\
\hline
\end{tabular}


Simulink block diagram of the developed technique is shown in Fig. 7. The test signal is obtained from Scope 1, while Figs. 2 to 6 are

Distortion due to Nonlinear distortion

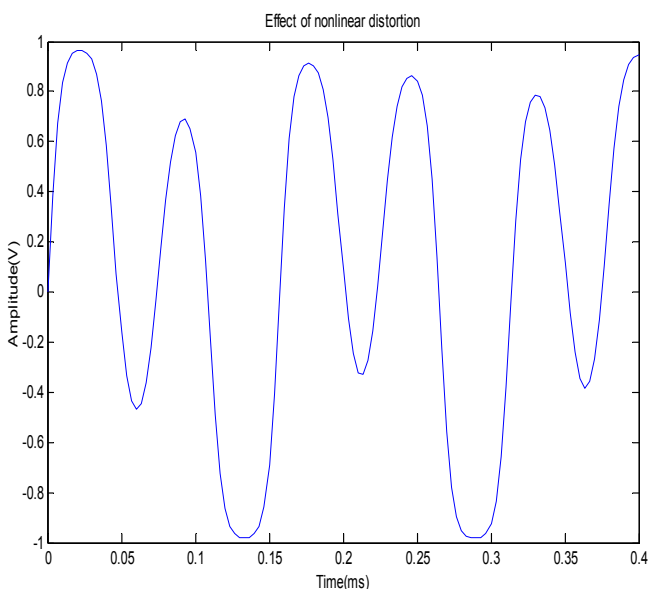

Fig. 3a. Distortion on test signal due to nonlinear distortion

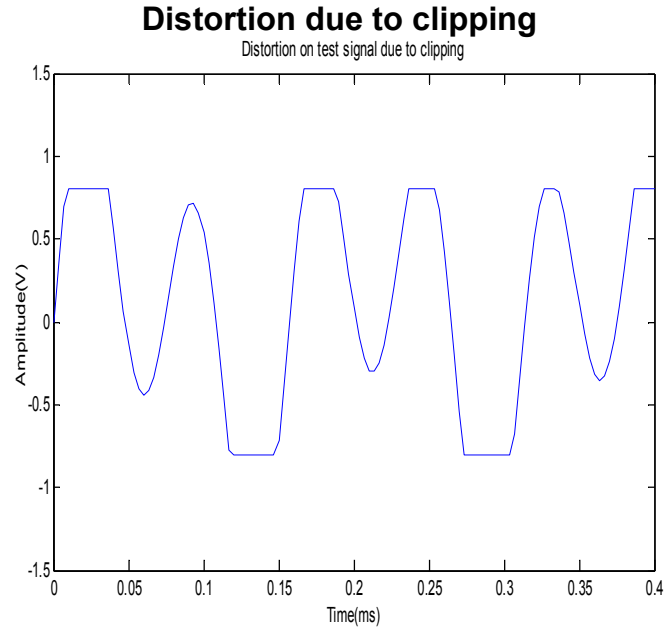

Fig. 4a. Distortion on test signal due to clipping obtained from scope. Fig. 8 shows the block diagram of the proposed analogue circuit implementation of equation 3 .

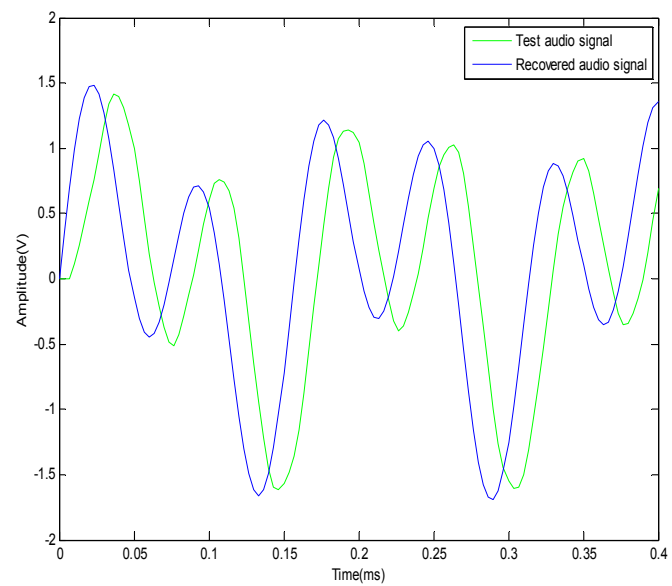

Fig. 3b. Plot of test signal and recovered playback audio signal (Nonlinearity)

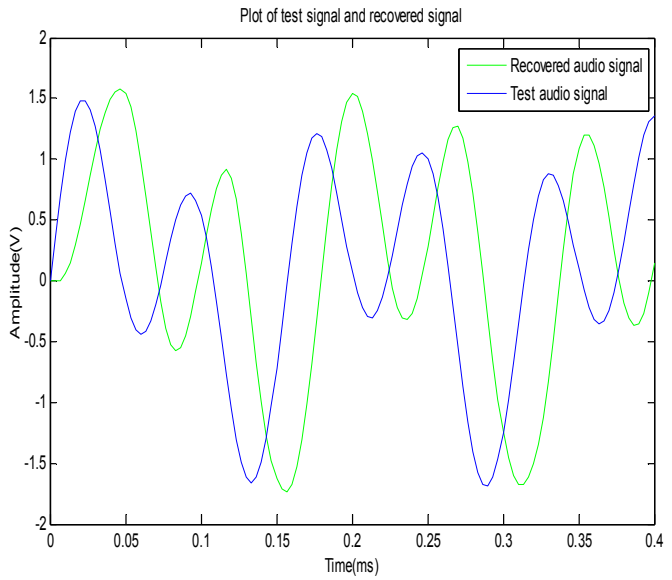

Fig. 4b. Plot of test signal and recovered signal (Clipping)

Table 2. Total harmonic distortion ( $5^{\text {th }}$ order) due to clipping and nonlinear distortion

\begin{tabular}{lll}
\hline Distortion & THD (distorted playback signal) & THD (after correction of distortions) \\
\hline Clipping & $-1.6 \mathrm{~dB}$ & $-40.32 \mathrm{~dB}$ \\
Nonlinear defect & $-1.6 \mathrm{~dB}$ & $-40.03 \mathrm{~dB}$ \\
\hline
\end{tabular}

Table 3. Signal to noise and distortion ratio (SINAD)

\begin{tabular}{lll}
\hline Distortion on test signal & $\begin{array}{l}\text { SINAD of distorted } \\
\text { playback signal }\end{array}$ & $\begin{array}{l}\text { SINAD at the output (after } \\
\text { correction of distortions) }\end{array}$ \\
\hline Clipping, nonlinearity, scratch and AWGN & $-0.43 \mathrm{~dB}$ & $51.3 \mathrm{~dB}$ \\
\hline
\end{tabular}


Distortion due to scratches on the tape surface

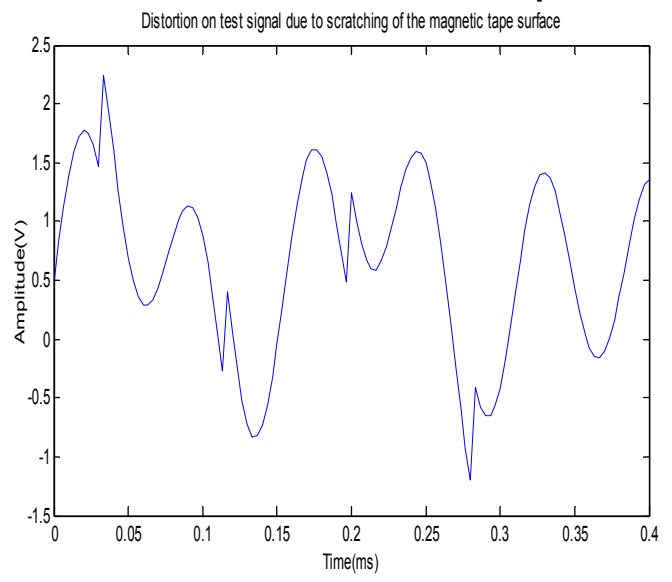

Fig. 5a. Distortion on test signal due to scratching of the magnetic tape surface

Distortion due to AWGN, clipping, scratch and nonlinearity

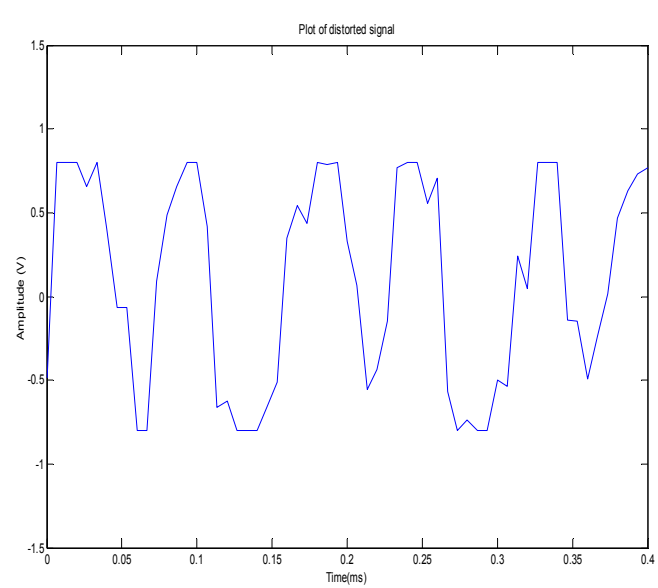

Fig. 6a. Multiple distortions on test signal due to AWGN, clipping, scratch and nonlinearity

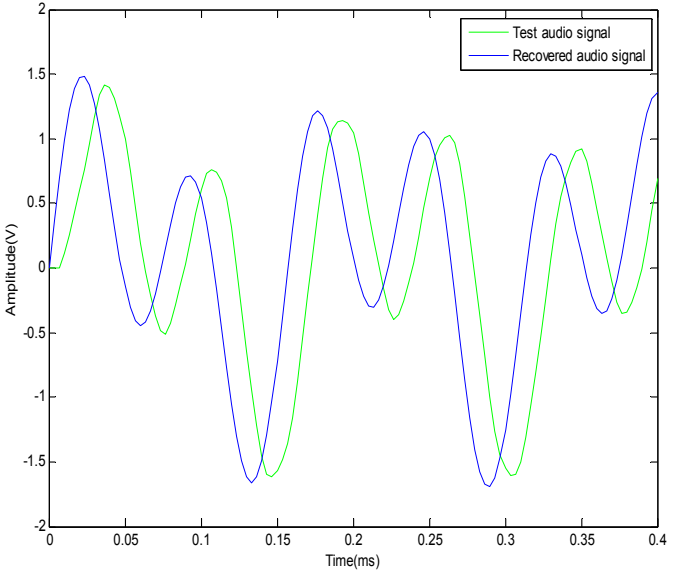

Fig. 5b. Plot of test signal and recovered signal (Scratching)

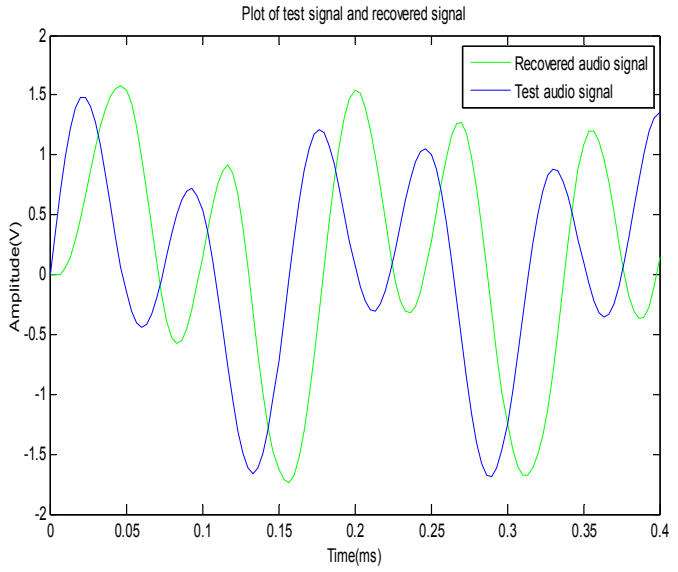

Fig. 6b. Plot of test signal and recovered signal (Multiple distortions)

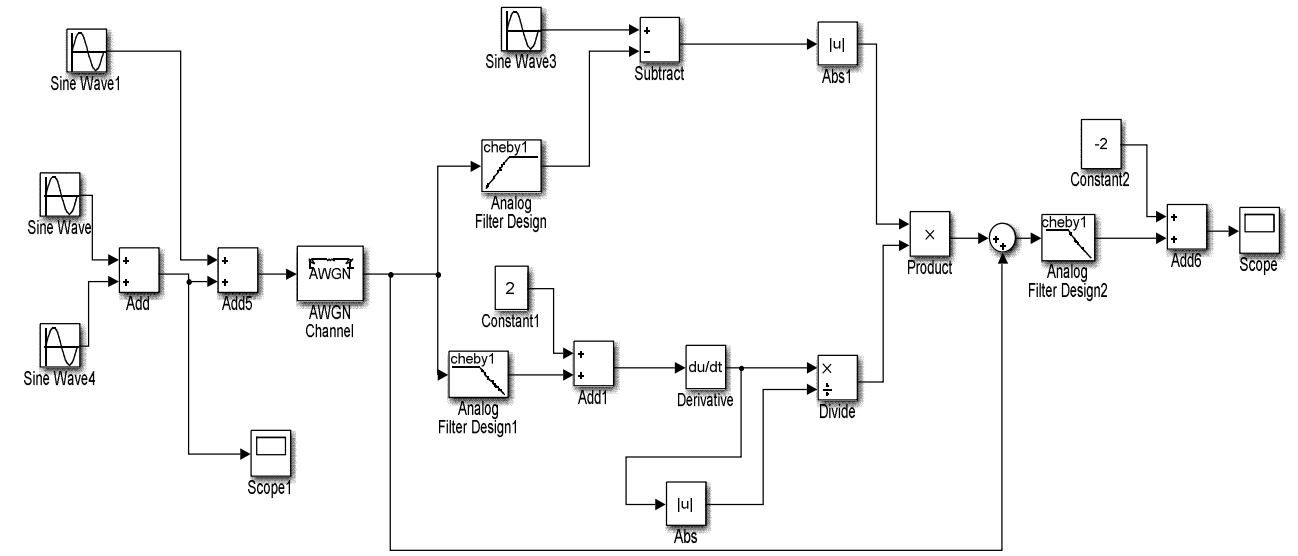

Fig. 7. Simulink block diagram of the developed technique 
Atijosan et al.; BJAST, 9(4): 338-345, 2015; Article no.BJAST.2015.273

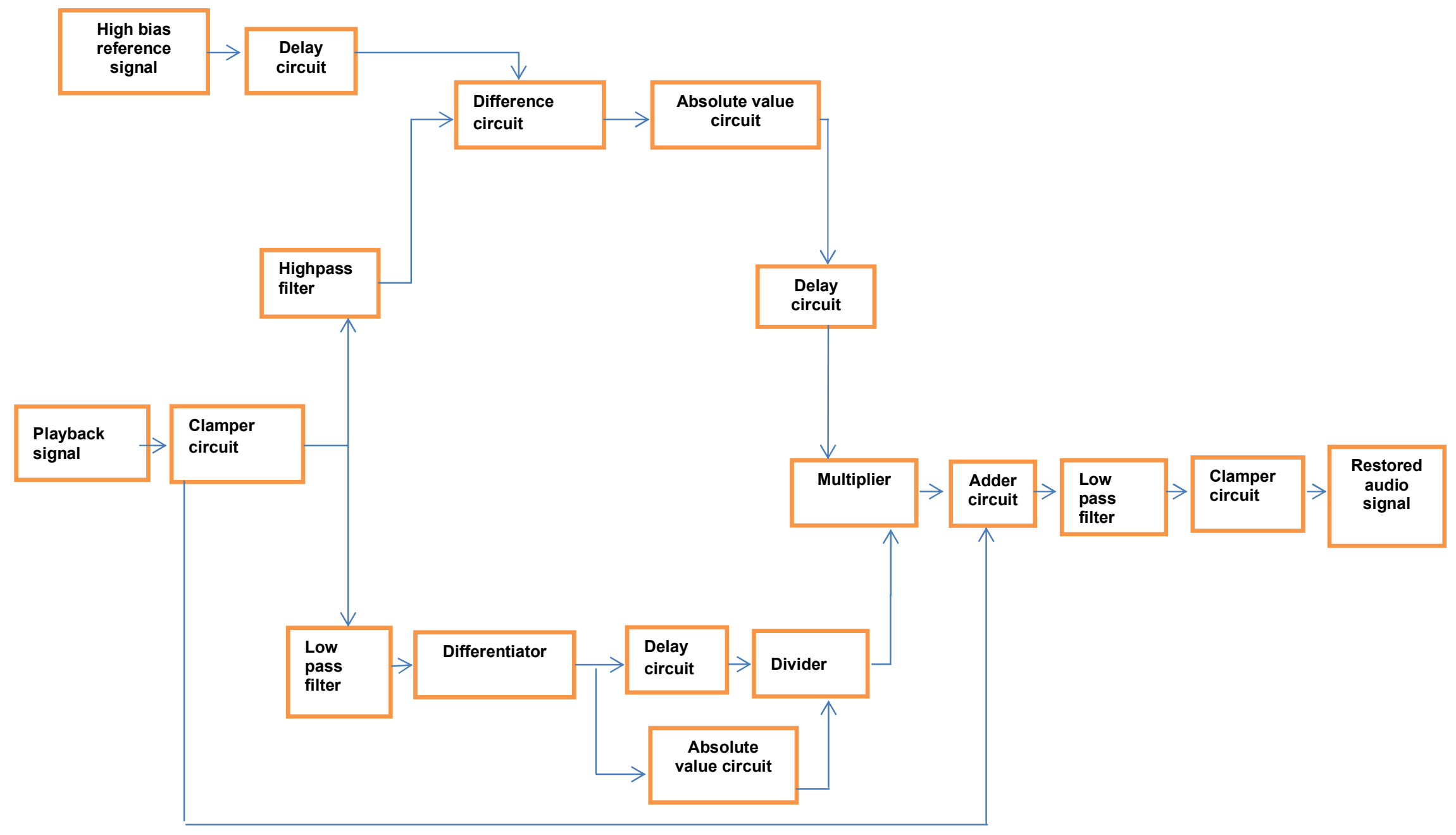

Fig. 8. Block Diagram of proposed analogue circuit implementation of equation three 


\section{CONCLUSION}

Results obtained from the developed analogue techniques brought out the following conclusions;

i. The developed analogue technique was able to correct for noise, clipping, scratches on the tape surface and nonlinear distortions in the playback audio signal.

ii. The developed analogue technique was able to correct for distortions that arises in the playback signal when the polarity of the error signal and that of the distorted playback signal differs.

iii. Some distortions were not perfectly restored; this may be due to the occurrence of breakages in the high frequency biased signal when the distortion is severe

The technique will be useful in restoring the fidelity of playback audio signals from magnetic cassette tapes.

\section{COMPETING INTERESTS}

Authors have declared that no competing interests exist.

\section{REFERENCES}

1. Scheidegger S. Restoration of audio recordings corrupted by nonlinear distortions (M.Sc thesis). Swiss Federal Institute of Technology, Zurich; 2010.

2. Bressan F, Canazza S. Digital Philology in Audio Long-term Preservation: A multidisciplinary project on experimental music. Procedia Computer Science. 2014; 38:48-51.

3. Jafarkhani $H$, Andersson $D$, Heal $A$, Teran S. Cassette Tape Signal Processing; 2009.

Available: http://eecs.richardnelson.com (On 24 $4^{\text {th }}$ October 2013 Date accessed: $24^{\text {th }}$ October 2013)
4. Richard H. Tape degradation factors and challenges in predicting tape life. Association for Recorded Sound Collections (ARSC) Journal. 2008;34(2): 240-241.

5. Richardson S. WPI Technical Theatre Handbook; 1996.

Available:http://www.gweep.net/ prefect/p ubs /iqp/technical theatre handbook.pdf (Date accessed: $4^{\text {th }}$ of July, 2012)

6. Parras-Moral J, Canadas-Quesada FJ, Vera-Candeas P, Ruiz-Reyes N. Audio restoration of solo guitar excerpts using a excitation-filter instrument model. Proceedings of the Sound and Music Computing Conference 2013, SMC 2013, Stockholm, Sweden.

7. Godsill S, Rayner P. Digital restoration: A statistical model based approach, Springer-Verlag, Berlin; 1998.

8. Paul J, Tunstall D. Digital audio processing training manual, Third edition; 2004. Available: www.dacaudio.com

9. Bako T. Restoration of Nonlinearly Distorted Optical Soundtracks using Regularized Inverse Characteristics (Doctoral Dissertation). Budapest University of Technology and Economics, Budapest, Hungary; 2004.

10. Wallaszkovits $\mathrm{N}$, Hetzer T, Pichler H. Drift and Wow Correction of Analogue Magnetic Tape Recordings in the Analogue Domain Using HF-Bias Signals. In Audio Engineering Society Convention 136. Audio Engineering Society; 2014.

11. Thakur C, Singh S. Correction of WOW and flutter in audio signals using least mean square algorithm. International Journal of Computer Applications. 2014; 85(16):46-52.

12. Czyzewski A, Andrzej C, Andrzej K, Jozef K, Maciej K, Przemek M. DSP techniques for determining "Wow" distortion, Journal of the Audio Engineering Society. 2007; 55(4):266.

13. Howarth J, Wolfe J. Correction of wow and flutter effects in analogue tape transfers. Audio Engineering Society, $117^{\text {th }}$ International Convention, New York, USA. 2004;2-5. 
14. Sokunbi M. Development of a novel compensation technique for signal
deterioration in ageing recorded audio

tapes (M.Sc Thesis). Department of

Electronic/Electrical Engineering, Obafemi Awolowo University, Ile-Ife, Nigeria; 2005.

(c) 2015 Atijosan et al.; This is an Open Access article distributed under the terms of the Creative Commons Attribution License (http://creativecommons.org/licenses/by/4.0), which permits unrestricted use, distribution, and reproduction in any medium, provided the original work is properly cited.

\section{Peer-review history:}

The peer review history for this paper can be accessed here: http://www.sciencedomain.org/review-history. php? $\mathrm{iid}=1139 \& i d=5 \&$ aid $=9401$ 